\title{
CONEXÕES ENTRE CONTEXTOS: A FICÇÃO PERSUASIVA DE MARILYN STRATHERN ${ }^{1}$
}

\author{
Manoel Cláudio Mendes Gonçalves da Rocha ${ }^{2}$ \\ Robson Cardoso de Oliveira ${ }^{3}$
}

Fora de contexto: as ficções persuasivas da antropologia é uma obra originada da apresentação de Marilyn Strathern durante a Palestra Frazer ${ }^{4}$ em 1986 e posteriormente publicada no volume 28 da Current Anthropology e que só agora em 2013, tivemos a oportunidade de ter uma tradução em português.

Grandes nomes da Antropologia como Bronislaw Malinowski, Claude LéviStrauss, Clifford Geertz, Marshall Sahlins e outros realizaram apresentações na Palestra Frazer, a qual Strathern fora incluída nesse grupo seleto: a autora foi a primeira a receber o título de Dame que equivale ao de Sir dentro da antropologia britânica. Ela possui obras de referências como Women in between (1972), O Gênero da Dádiva (1988) e Partial Connections (1991), entre outras.

Marilyn Strathern possui uma significativa produção dentro dos Estudos de Gênero, tornando-se uma referência para o Movimento Feminista a partir da década de 1980, principalmente após a publicação de $O$ Gênero da Dádiva. Sua intenção era de, com base nos estudos feministas, permitir uma transformação do olhar da antropologia para mulheres, homens e maneiras de escrever sobre cultura e sociedades (Strathern, 1988).

Um caminho interessante para compreendermos Fora de Contexto é tentar desvendar o que a autora quer nos dizer com a escolha deste título. Daí surgirem algumas perguntas: que contexto será este do qual a autora está falando? Mais ainda, de que condições específicas implicam em um estar dentro ou "fora de contexto"? Antes de entrarmos em uma empreitada em busca dos sentidos mais profundos do termo,

\footnotetext{
${ }^{1} \mathrm{O}$ texto de Strathern mostra-se de extrema relevância por ter sido apresentado primeiramente na Palestra Frazer de 1986, buscando analisar questões em torno do próprio autor que dá título ao evento, bem como por contribuir com o debate acerca da escrita etnográfica e da autoridade do etnógrafo incitado pela crítica pós-moderna e sua relação com a literatura antropológica "moderna".

${ }^{2}$ Universidade Federal do Pará, Brasil.

${ }^{3}$ Universidade Federal do Pará, Brasil.

${ }^{4}$ Palestra realizada anualmente desde 1922, itinerantemente, entre as universidades de Cambridge, Glagsgow, Oxford e Liverpool.
} 
lancemos o olhar para o questionamento acerca do qual Strathern se debruça ao longo do texto.

Logo nos primeiros parágrafos de sua narrativa, Strathern comenta sobre como sua geração foi formada para apreciar as ideias de James Frazer como "antiquadas antes mesmo de o autor tê-las escrito" (Strathern, 2012: 27). Segundo a autora, a antropologia moderna britânica afirmava certo caráter antifrazeriano, olhando sua obra com desdém e considerando-a superada, ultrapassada. O grande problema que ela busca compreender é porque a obra Folk-lore in the Old Testament de Frazer, aclamada por revistas teológicas e literárias à época, além de ter exercido um poder duradouro, de modo geral, sobre a sociedade de seu tempo, era ao mesmo tempo tão ilegível para os antropólogos modernos e, por conseguinte, seu autor não teria lugar entre eles, ou seja, estaria "fora de contexto".

O interesse da autora não é simplesmente refletir sobre a história da antropologia. Pelo contrário, o que Strathern procura é apurar a ideia de que possíveis leituras do passado da disciplina estão relacionadas a uma perspectiva ancorada no presente. Ela demonstra como Malinowski, figura canônica no campo antropológico que teria “destronado" Frazer ${ }^{5}$, também assumiu a condição de ultrapassado para a geração de antropólogos pós-modernos, tal como seu antecessor. Em outros termos, são "as ideias que estão no ar" ou um "contexto presente" que irá delinear o caráter legível/ilegível, pertinente/ultrapassado de determinada obra com relação à historicidade da disciplina científica na qual está inserida.

Seguindo este caminho nos damos conta dos sentidos que Marilyn Strathern irá atribuir ao termo "contexto" no desenvolver de sua narrativa. A obra revela pelo menos três formas diferentes: os dois primeiros itens apontados abaixo aparecem ao longo da narrativa da autora, enquanto o terceiro refere-se ao neologismo con-text presente nos comentários de Tyler e Marcus (2013), que entre os elementos que seguem a obra somam importante contribuição ao debate evocado por Strathern em Fora de Contexto.

\footnotetext{
${ }^{5}$ Com a entrada em cena de Malinowski, Frazer é encaminhado para os bastidores com textos ditos antiquados e ilegíveis, mas o motivo principal para essa mudança de cenários está relacionado à mudança das investigações antropológicas: saindo de uma perspectiva diacrônica para a sincrônica, edificada a partir da Escola Estrutural-Funcionalista Britânica - a presença do antropólogo em campo passa a ser privilegiada em detrimento do antropólogo de gabinete, figura a qual Frazer fora marcado.
} 


\section{“Contexto" enquanto perspectiva cultural}

Strathern tece interessante crítica ao dualismo "observador" e "observado" (nós/eles) engendrado pelos antropólogos modernistas, e a respeito do artifício analítico de utilizar categorias próprias da sociedade ocidental a fim de tornar acessíveis e inteligíveis a "estranheza" e o caráter "exótico" das instituições e práticas sociais dos grupos estudados (por exemplo, acionar elementos como as relações de parentesco e as práticas da dádiva por meio de denominações e aspectos de uma economia ocidental). Como coloca a própria autora: "Dessa forma, manipular os próprios conceitos para conceitualizar aqueles construídos como alheios, estabelecia distâncias entre escritor, leitor e subjeto ${ }^{6}$ de estudo (Strathern, 2013: 57). O que ela está contrapondo é o fato de nós antropólogos muitas vezes construirmos nossa narrativa embaralhando os "contextos" (de um lado, a sociedade e cultura dos interlocutores, do outro, a estrutura acadêmica e política que precede o pesquisador), com o intuito de "borrar" as diferenças entre estes.

\section{“Contextos" de produção de conhecimento}

Strathern apresenta ao longo da obra, três contextos que revelam momentos distintos da história da antropologia: a "evolução" de James Frazer, o "modernismo" de Malinowski e o "pós-modernismo" dos debates antropológicos arguidos por seus contemporâneos à época de publicação da obra ${ }^{7}$. Aqui a autora direciona a discussão para o "contexto" acadêmico, o meio que legitima e autoriza o que é produzido pelo pesquisador conferindo ao seu trabalho o caráter científico. Deste modo, a trajetória de uma disciplina científica configura-se a partir da mudança de contextos. Em outras palavras, por trás de todo campo de produção de conhecimento há um devir científico promovido pelas estruturas de poder instauradas nas instituições acadêmicas e centros

\footnotetext{
${ }^{6}$ O termo "subjeto" é utilizado na tradução como alternativa para a palavra subject, que no inglês pode significar "sujeito", "objeto", assunto ou mesmo uma referência à "disciplina" antropológica. Subjeto abarca aqui esta variedade de sentidos, pois refere-se ao "assunto" investigado, conferindo-lhe mais do que a mera condição de objeto de estudo, na medida em que são sujeitos capazes de argumentar e contestar a autoridade do antropólogo.

${ }^{7}$ É significativo ressaltar que o livro foi publicado em 1987, ou seja, Strathern está falando do contexto pós-moderno no período em que às criticas as etnografias clássicas estão sendo edificadas.
} 
de pesquisas, que desenvolvem os parâmetros de construção de saber, atualizam os paradigmas que orientam a disciplina, além de ditar o que é marginal, defasado ou ultrapassado.

\section{“Con-text”, o "jogar com o texto"}

O termo revela um terceiro significado peculiar nos comentários de Tyler e Marcus quando estes fazem um trocadilho com a palavra inglesa con-text (con = trapaça, text $=$ texto), referindo-se o ato de "jogar com o texto" característico da escrita antropológica. Veja bem, o sentido de jogar com o texto não significa uma espécie de "falseamento" do que é narrado por meio da escrita. Na verdade, este "jogo" diz respeito às estratégias retóricas e artifícios do texto através do qual nós antropólogos construímos nossa narrativa etnográfica. Lembrando, obviamente, que estes recursos variam de acordo com o "contexto" no qual é produzida a etnografia, logo, podem revelar-se nas sinédoques e artifícios totalizantes do "realismo etnográfico" (Marcus, Cushman, 1982) característico das etnografias modernas, ou nos jogos de multivocalidade presentes nas narrativas dialógicas e polifônicas.

A prática de "inventar" a cultura do Outro reforçava as atribuições de significados exercidas pelos antropólogos acionadas a partir de sua própria cultura ${ }^{8}$ e inscritas em uma relação etnocêntrica. Strathern propõe que o fazer antropológico deve ir além da "visão moderna" que considera a etnografia enquanto observação do Outro e a construção de categorias e conceitos que atribuam sentido às suas práticas cotidianas, partindo do entendimento de que a construção do texto etnográfico pode constituir uma ferramenta através da qual tais categorias tendem a ser "negociadas", isto é, onde antropólogo, interlocutor e leitor podem jogar com os diferentes "contextos" evocados pela narrativa.

A autora faz uma interessante analogia ao comparar o pós-modernismo na antropologia ao chamado "pós-modernismo" nos Estudos de Gênero. Neste último,

\footnotetext{
${ }^{8}$ Roy Wagner (2012) questiona se o antropólogo "inventa" a cultura do Outro e se essa invenção é justificada a partir do momento em que o pesquisador se utiliza da objetividade relativa, ou seja, passa a experimentar os modos de vida de seu grupo pesquisado e através das descobertas das práticas vividas, esse pesquisador "inventa" a cultura do Outro e consequentemente reinventa a sua própria, retirando-a da lógica do "invisível" e passando-a para o "visível". O antropólogo percebe o dinamismo da sua cultura e a do Outro, inferindo que não é algo dado, mas sim fruto de uma construção social.
} 
as/os autoras/es jogam com o contexto e procuram, de modo interdisciplinar, o diálogo entre várias áreas de conhecimento como a História, Literatura e a Antropologia, no intuito de fugir na operação de trabalhar com "um único contexto como moldura organizativa" (Strathern, 2013: 79).

O "jogar com o texto" (con-text) está diretamente ligado a uma das discussões centrais da obra de Strathern: o caráter ficcional ${ }^{9}$ do texto etnográfico. A autora caracteriza as etnografias como "ficções persuasivas": em busca da aceitação de nossos trabalhos enquanto obras legítimas de valor científico edificamos o texto etnográfico com base em uma apreensão/percepção da vida social - oriunda da experiência do encontro com o Outro - e a transportamos para a escrita através de uma variedade de esquemas e estratagemas narrativos, compondo uma trama engenhosa que em muito se distancia da experiência anterior. Como pode ser possível reproduzir no texto uma experiência que se passou em um ambiente totalmente diferente da academia, se não através de uma construção narrativa que não existiria de outro modo senão por meio de uma ficção. Avançando na discussão, não se pode esquecer que esta ficção possui o intuito de convencer/"persuadir" alguém sobre alguma verdade. Resta-nos questionar, como bem lembra Jarvie (2013) em seus comentários à obra de Strathern, quem são os sujeitos que estamos querendo persuadir? Nossos pares, os colegas de profissão ou mesmo uma autoridade canônica do campo antropológico? E nossos interlocutores, o que pensam disso? Seriam nossos textos realmente "verdades" para estas pessoas?

Daí chegarmos a outro ponto interessante dos problemas levantados por Strathern (o que nos leva a observar os trabalhos da autora que sucederam esta obra, onde ela aprofunda estas reflexões). Entre os debates dos antropólogos pós-modernos a respeito da autoridade etnográfica e a escrita antropológica, James Clifford propõe a busca de verdades parciais ${ }^{10}$. Com o intuito de avançar nesta discussão, Strathern coloca uma

\footnotetext{
${ }^{9}$ A noção de ficção antropológica de Clifford Geertz, segundo Caldeira (1988), seria uma ponte entre dois mundos culturais, resultando na revelação de uma realidade que o antropólogo conhece, explana, interpreta e experimenta, uma ficção de nós/eles. Essa ficção, até hoje, faz parte do fascínio do exercer a antropologia, ora criticada, ora exaltada. Quem critica a obra de Malinowski, em algum momento, em outro a exalta. Há perspectivas positivas e negativas entranhadas nas produções etnográficas clássicas.

${ }^{10} \mathrm{O}$ autor considera a etnografia como a busca por canais de diálogos, através dos quais a pluralidade de vozes presentes no encontro etnográfico permite a produção de "verdades parciais" (Clifford, 1991). Para James Clifford (1998), a experiência etnográfica reúne tipos de discursos distintos: de um lado, o discurso acadêmico versado pelo antropólogo e do outro, discursos das mais variadas ordens sociais e históricas, aqueles enunciados pelos sujeitos junto aos quais o pesquisador realiza seu trabalho. Partindo da crítica às etnografias clássicas, onde o antropólogo se impunha como única voz autorizada a transmitir
} 
perspectiva alternativa: a ideia de "conexões parciais" (Strathern, 2004). A proposta seria utilizar o texto etnográfico como ferramenta através da qual possa ser possível colocar diferentes contextos em evidência: não apenas o contexto do qual vem o pesquisador ou aquele do interlocutor no qual ele almeja se inserir, como também o contexto de onde parte o leitor e o contexto do campo de produção de conhecimento que acolhe o debate.

O que interessa à autora não é a construção de verdades ou argumentos convincentes, o que lhe importa é a possibilidade de intercâmbio de experiências e troca de saberes entre sujeitos de diferentes contextos e os efeitos que estas conexões podem proporcionar. Na medida em que a transposição de contextos nunca é completa ou inteira, pois sempre de caráter parcial, a narrativa etnográfica deve ser o meio através do qual sejam ressaltados os contrastes, permutas e mediações oriundas do choque/contato entre contextos.

É valido sublinhar o diálogo de Marilyn Strathern com os estudos feministas, fator que influencia os questionamentos da autora acerca do espaço destinado às mulheres nas produções etnográficas pós-modernas. "Jogando com o contexto", Strathern retoma o pós-modernismo na antropologia problematizando a sua preocupação centrada no elemento textual, o exame sobre a autoridade etnográfica e a respeito da adoção do dialogismo e da polifonia. Nas considerações da antropóloga, a geração dos pósmodernos continuou, porém, a replicar produções cuja visão do Outro permaneceu, em certa medida, sob a égide do Ocidente, etnocêntrica, na perspectiva do antropólogo branco e heterossexual. Ou seja, por mais que esses "sujeitos observados" ganhassem voz, elas/es continuavam inscritos em molduras que retratavam o não-ocidente, $\mathrm{o}$ colonizado, condição essa criticada por feministas à Antropologia Pós-Moderna.

O fazer etnográfico em nossos dias coloca o etnógrafo sujeito a avaliações rigorosas e o faz responsável por uma série de compromissos, tanto com a comunidade acadêmica da qual faz parte quanto com o grupo social junto ao qual desenvolve suas pesquisas. Pensar a prática antropológica no cenário contemporâneo é refletir não apenas sobre a pessoa do antropólogo enquanto escritor/autor, mas compreender que a

conhecimento, Clifford (1998) propõem uma etnografia polifônica e dialógica como o caminho para uma relação mais simétrica entre pesquisador e pesquisado, logo, o meio de se alcançar "verdades" cada vez mais parciais, pois fundadas na multivocalidade. 
própria escrita etnográfica, por mais subjetiva que seja, é atravessada por relações de poder engendradas no meio acadêmico - que validam ou não o trabalho do antropólogo, conferindo-lhe valor somente se este está adequado à apreciação científica - e pelas condições específicas em que se estabelecem as relações entre pesquisador e interlocutor. A análise minuciosa e atenta desta série de fatores é, por certo, um dos percursos que pode nos levar a compreender o que faz uma etnografia estar dentro ou fora de contexto.

\section{Referências}

CALDEIRA, T.P.R. A presença do autor e a pós-modernidade em Antropologia. Novos Estudos, $\mathrm{n}^{\circ}$ 21. 1988.

CLIFFORD, J. Sobre a autoridade etnográfica; In: Clifford, J. A experiencia etnográfica: antropologia e literatura no século XX (org. Gonçalves, J.R.S.) Ed. da UFERJ, pp. 17-62. 1998.

CLIFFORD, J. Introducción: Verdades Parciales. In: CLIFFORD, J.; MARCUS, G. Retoricas de la antropologia. Barcelona: Júcar, pp 25-60. 1991.

MARCUS, G.; CUSHMAN, D. Ethnographies as texts. Annual Review of Anthropology, Vol. 11. pp. 25-69. 1982.

STRATHERN, Marilyn. Partial Connections. Updated Edition. Oxford: Altamira Press. 2004 [1991].

O Gênero da Dádiva: problemas com as mulheres e problemas com a sociedade na Melanésia. Trad. André Vilalobos. Campinas, São Paulo: Editora da UNICAMP. 2006 [1988].

Fora de Contexto: as ficções persuasivas da Antropologia. Trad. Tatiana Lotierzo \& Luis Felipe Kojima Hirano. São Paulo: Terceiro Nome. 2013 [1987].

WAGNER, Roy. A Invenção da Cultura. Trad. Marcelo Coelho de Souza \& Alexandre Morales. São Paulo: Cosac Naify. 2012 [1938].

Recebido em: 20/08/2013

Aprovado em: 10/09/2013 